\title{
Spatiotemporal Characteristics Analysis of Environmental Sensitivity of Drought Disaster in Xilingol Grassland
}

\author{
Qiaofeng Zhang ${ }^{1,2,3,4}$, Guixiang $\mathrm{Liu}^{2}$, Hongbo $\mathrm{Yu}^{1,3,4}$, Shan Yu ${ }^{1,3,4}$, Yuhai Bao ${ }^{1,3}$ \\ ${ }^{1}$ College of Geographical Science, Inner Mongolia Normal University, Hohhot 010022, China \\ ${ }^{2}$ Institute of Grassland Research of Chinese Academy of Agricultural Sciences, Hohhot 010010, \\ China \\ ${ }^{3}$ Inner Mongolia Key Laboratory of Remote Sensing and Geography Information System, Hohhot \\ 010022, China \\ ${ }^{4}$ Inner Mongolia Key Laboratory of Disaster and Ecological Security on the Mongolian Plateau, \\ Hohhot 010022, China

\section{锡林郭勒草原干旱孕灾环境敏感性时空特征分 \\ 析 \\ 张巧凤 ${ }^{1,2,3,4}$, 刘桂香 ${ }^{2}$, 于红博 ${ }^{1,3,4}$, 玉山 ${ }^{1,3,4}$, 包玉海 ${ }^{1,3}$ \\ 内蒙古师范大学地理科学学院, 内蒙古 呼和浩特 010022 \\ ${ }^{2}$ 中国农业科学院草原研究所, 内蒙古 呼和浩特 010010 \\ ${ }^{3}$ 内蒙古自治区遥感与地理信息系统重点实验室, 内蒙古 呼和浩特 010022 \\ ${ }^{4}$ 内蒙古自治区蒙古高原灾害与生态安全重点实验室, 内蒙古 呼和浩特 010022}

\begin{abstract}
:
Under the background of global warming, drought is one of the main meteorological disasters in China. The risk assessment of drought disaster is the premise of risk early warning and actual disaster evaluation, and it is the basis of disaster prevention and reduction. In this paper,meteorological data, remote sensing data, soil moisture data and basic geographic information data were used to extract the environmental sensitivity assessment factors of the grassland drought disaster. According to the analytic hierarchy process and the expert evaluation method, the weight of each index was determined. The linear weighted comprehensive method and the system clustering method were used to
\end{abstract}

analyzeand zone the spatiotemporal characteristics of environmental sensitivity of drought disaster in Xilingol Grassland.

Keywords: drought; disaster environment; sensitivity; AHP

摘要:

在全球气候变暖的大背景下, 干旱灾害 是我国面临的主要气象灾害之一, 干旱灾害 风险评估是风险预警与实际灾情评价的前 提, 是防灾减灾的基础。本文应用气象数据、 遥感数据、土壤墑情数据和基础地理信息数 据等, 提取草原干旱孕灾环境敏感性评估因 子, 根据层次分析法和专家评价法确定各指 标的权重，采用线性加权综合法和系统聚类 方法分析锡林郭勒草原干旱孕灾环境敏感 性的时空特征并进行空间区划。 
关键词: 干旱; 孕灾环境; 敏感性; 层次分 析法

在全球气候变暖的大背景下, 干旱灾害 是我国面临的主要气象灾害之一, 干旱灾害 风险评估是风险预警与实际灾情评价的前 提, 是防灾减灾的基础, 其成果可为防灾减 灾提供科学依据。草原干旱灾害是指由于外 界环境因素变化导致土壤和植被的水分亏 缺, 植被的正常返青、生长和营养成分积累 受限, 导致草原产草量、载畜量和牛羊肉等 产量下降, 进而影响农牧民正常生产生活水 平和秩序的现象。草原干旱灾害与传统农业 干旱灾害既有区别又有联系, 涉及到大气、 土壤、植被、牲畜和人类等多方面因素。灾 害的风险评价主要根据有关自然灾害风险 理论 $[1-10]^{1}$, 从孕灾环境的敏感性、致灾因 子的危险性、承灾体的暴露性和易损性以及 防灾减灾能力四个方面对灾害风险进行综 合评估。其中孕灾环境的敏感性是指灾害发 生时自然环境和人文环境的协调稳定程度, 锡林郭勒草原属温带干旱、半干旱气候区, 年降水量少、干燥度大且时空分布不均匀, 极易形成干旱灾害。加之长期围栏放牧和超 载过牧等人为原因, 导致草原牧区应对自然 灾害的能力降低。鉴于草原干旱灾害的复杂 性和影响因子的多样性, 本文基于自然灾害 风险理论, 根据层次分析法和专家评价法确 定干旱孕灾环境各指标的权重, 应用气象数 据、遥感数据、土壤墒情数据和基础地理信 息数据提取锡林郭勒草原各旗县市相关因 子的实际值, 采用线性加权综合法和系统聚 类方法评价各旗县市干旱孕灾环境敏感性 的时空特征并进行空间区划。层次分析法被 广泛应用于各类灾害风险评估研究中 [11], 是灾害风险评估的有效方法之一。

\section{1. 研究区概况}

锡林郭勒草原位于中国北方的内蒙古 自治区中部, E $111^{\circ} 09^{\prime}-120^{\circ} 01^{\prime}, \mathrm{N} 41^{\circ}$ $35^{\prime}-46^{\circ} 46^{\prime}$ 。地势北低南高, 东、南部 为大兴安岭和阴山山脉延伸余脉的交错地 段, 西、北部地势较平坦, 为高原草地。锡 林郭勒草原属于中温带干旱半干旱大陆性 气候, 年平均气温 $0-4^{\circ} \mathrm{C}$, 最高气温在 7
月份, 平均为 $22^{\circ} \mathrm{C}$; 年降水量 $200-360 \mathrm{~mm}$, 由东南向西北递减, 降水量主要集中在 6-9 月; 年日照时数为 $2800-3200 \mathrm{~h}, 4-9$ 月 太阳辐射约占全年的 $60 \%$ 左右; 该研究区生 长季气温适宜, 光照充足, 是中国北方重要 的生态屏障和畜牧业生产基地, 也是我国最 大的草原生态系统类型的自然保护区。水平 地带性土壤类型自东向西有黑钙土、栗钙土 和棕钲土。根据 1:100 万内蒙古自治区植被 类型图矢量化结果, 锡林郭勒草原植被类型 主要分为四大类, 即草甸草原、典型草原、 荒漠草原和沙地植被 (图 1) [12-13]。

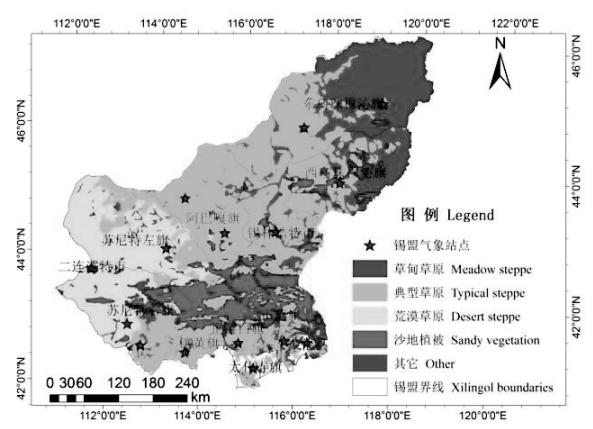

图 1 锡林郭勒草原

\section{2. 数据与方法}

\section{1 数据处理}

根据草原牧区干旱孕灾环境敏感性评 估指标 (表 1), 利用遥感数据（2000 2014 年)、气象数据 (2000 2014 年) 和基础地理 信息数据, 通过直接使用或者模型计算等统 计 12 个旗县市各指标的实际值, 并应用极 差法对所有指标进行无量纲的标准化处理 (公式 1), 其中时间特征分析对各旗县市多 年的指标值按照发展类和限制类指标分别 进行标准化处理; 空间特征分析对每年各旗 县市的指标值按照发展类和限制类指标分 别进行标准化处理。对发展类指标的标准化:

$$
X_{i j}^{\prime}=\left(X_{j \max }-X_{i j}\right) /\left(X_{j \max }-X_{j \text { min }}\right)
$$

对限制类指标的标准化:

$$
X_{i j}^{\prime}=\left(X_{i j}-X_{j \text { min }}\right) /\left(X_{j \text { max }}-X_{j \text { min }}\right)
$$

其中, $X_{i j}^{\prime}$ 为 $X_{i j}$ 的标准化值; $X_{i j}$ 为第 $i$ 年 (或旗县市) 的第 $j$ 指标的原始值; $X_{j \text { min }}$ 为 
第 $i$ 指标的最小值; $X_{j \text { max }}$ 为第 $i$ 指标的 第 $j$ 指标的最小值; $X_{j \text { max }}$ 为第 $j$ 指标的 最大值。 $X_{i j}^{\prime}$ 的取值区间为 $[0,1]$ 。

\section{2 草原干旱孕灾环境敏感性评价指标}

基于草原干旱灾害风险形成机理, 从气 候、地形、土壤和植被四个方面选择 10 个 $\left(\mathrm{C}_{1}\right.$ $\sim \mathrm{C}_{10}$ ) 因子用来评价草原干旱孕灾环境的敏 感性; 应用层次分析法和专家评价法相结合 确定各指标的权重 (表 1), 层次单排序和总 排序均通过了 $\mathrm{CR}<0.1$ 的一致性检验。

表 1 锡林郭勒草原干旱孕灾环境敏感性评估指 标及其权重

\begin{tabular}{lll}
\hline 目标层 $(A)$ & 指标层 $(C)$ & 权重 $(\mathrm{W})$ \\
\cline { 2 - 3 } & 降水量 $\left(\mathrm{C}_{1}\right)$ & 0.2339 \\
& 气温 $\left(\mathrm{C}_{2}\right)$ & 0.0914 \\
& 蒸散发 $\left(\mathrm{C}_{3}\right)$ & 0.1787 \\
& 风速 $\left(\mathrm{C}_{4}\right)$ & 0.0424 \\
& 土壤田间持水量 $\left(\mathrm{C}_{5}\right)$ & 0.0698 \\
孕灾环境 & 土壤含水量 $\left(\mathrm{C}_{6}\right)$ & 0.1494 \\
敏感性 $(\mathrm{A})$ & 草原类型 $\left(\mathrm{C}_{7}\right)$ & 0.0513 \\
& 植被覆盖度 $\left(\mathrm{C}_{8}\right)$ & 0.0887 \\
& 高程 $\left(\mathrm{C}_{9}\right)$ & 0.0259 \\
& 坡度 $\left(\mathrm{C}_{10}\right)$ & 0.0685 \\
\hline
\end{tabular}

2.3 草原干早孕灾环境敏感性评估方法

依据层次分析法和专家评价法确定各 指标的权重 (表 1), 利用线性加权综合法计 算孕灾环境敏感性 (公式 2), 所得值越大说 明干旱孕灾环境敏感性越高, 利用系统聚类 分析进行空间区划。

$$
S P D E=\sum_{i=1}^{10} C_{i} W_{i}
$$

式中, $S P D E$ 表示孕灾环境敏感性, $C_{i}$ $\left(0 \leq C_{i} \leq 1\right)$ 为第 $i$ 项指标的标准量化值, $W_{i}$ 为第 $i$ 项指标的权重 (表 1 )。

\section{3 结果分析}

\section{1 干旱孕灾环境敏感性时空特征}

时间上, 近 15 年各旗县市干旱孕灾环 境敏感性均呈波动变化趋势 (图 2)。以草甸 草原为主体的东乌珠穆沁旗和西乌珠穆沁 旗的变化曲线基本一致 (图 $2(\mathrm{~A})$ ), 东乌珠 穆沈旗的敏感性值在 0.06 0.72 之间, 峰值 出现在 2007 年, 最小值出现在 2013 年, 平 均值为 0.34 ; 西乌珠穆沈旗的敏感值在 $0.07 \sim 0.66$ 之间, 峰值出现在 2007 年, 最小 值出现在 2012 年, 平均值为 0.31 ; 二者均 在 2004 年、 2007 年、 2009 年和 2011 年出 现波峰, 在 2005 年、 2008 年和 2010 年出现 波谷, 其余年份的敏感值亦较接近。线性回 归分析表明, 近 15 年东西乌的干旱孕灾环 境敏感性均呈下降趋势 $(P>0.05)$ 。

以典型草原为主体的阿巴嘎旗和锡林浩 特市的变化曲线基本一致（图 $2(\mathrm{~B})$ ), 阿巴 嘎旗的敏感性值在 $0.18 \sim 0.66$ 之间, 峰值出 现在 2001 年, 最小值出现在 2012 年, 平均 值为 0.48 ; 锡林浩特市的敏感值在 $0.22 \sim 0.59$ 之间, 峰值出现在 2009 年, 最小值出现在 2011 年, 平均值为 0.42 ; 二者均在 2001 年、 2005 年、2007 年和 2009 年出现波峰, 在 2003 年、2006 年和 2008 年出现波谷, 其余年份 的敏感值亦较接近。线性回归分析表明, 近 15 年阿巴嘎旗和锡林浩特市的干旱孕灾环 境敏感性均呈下降趋势 $(P>0.05)$ 。

以沙地植被或农牧交错为主体的多伦 县、太仆寺旗、正蓝旗、正镶白旗和镶黄旗 变化曲线基本一致 (图 2 (C)), 其中多伦县 的敏感性值在 0.08 0.68 之间, 峰值出现在 2009 年, 最小值出现在 2003 年, 平均值为 0.43 ; 太仆寺旗的敏感性值在 $0.00 \sim 0.65$ 之 间, 峰值出现在 2011 年, 最小值出现在 2003 年, 平均值为 0.37 ; 正蓝旗的敏感性值在 0.08 0.72 之间, 峰值出现在 2009 年, 最小 值出现在 2003 年, 平均值为 0.43 ; 正镶白 旗的敏感性值在 $0.06 \sim 0.71$ 之间, 峰值出现 在 2007 年, 最小值出现在 2003 年, 平均值 为 0.47 ; 镶黄旗的敏感性值在 $0.04 \sim 0.68$ 之 间, 峰值出现在 2007 年, 最小值出现在 2003 年, 平均值为 0.45 ; 且均在 2001 年、 2005 
年、2007 年、2009 年和 2011 年出现波峰, 在 2003 年、2006 年、2008 年、2010 年和 2013 年出现波谷, 其余年份的敏感值亦较接 近。线性回归分析表明, 除多伦县的干旱孕 灾环境敏感性呈下降趋势外, 其余均呈上升 趋势, 但变化均不显著 $(P>0.05)$ 。

以荒漠草原为主体的二连浩特市、苏尼特 右旗和苏尼特左旗的变化曲线基本一致 (图 2 (D)), 其中二连浩特市的敏感性值在 0.09 0.68 之间, 峰值出现在 2005 年, 最小 值出现在 2003 年, 平均值为 0.47 ; 苏尼特 右旗的敏感性值在 $0.17 \sim 0.73$ 之间, 峰值出 现在 2005 年, 最小值出现在 2003 年, 平均 值为 0.45 ; 苏尼特左旗的敏感性值在 0.18 0.71 之间, 峰值出现在 2005 年, 最小 值出现在 2003 年, 平均值为 0.44 ; 且均在 2001 年、2005 年和 2009 年出现波峰,在 2003 年和 2012 年出现波谷, 其余年份的敏感值 亦较接近。线性回归分析表明, 苏尼特左旗 的干旱孕灾环境敏感性呈下降趋势, 二连浩 特市和苏尼特右旗呈上升趋势, 但变化均不 显著 $(P>0.05)$ 。
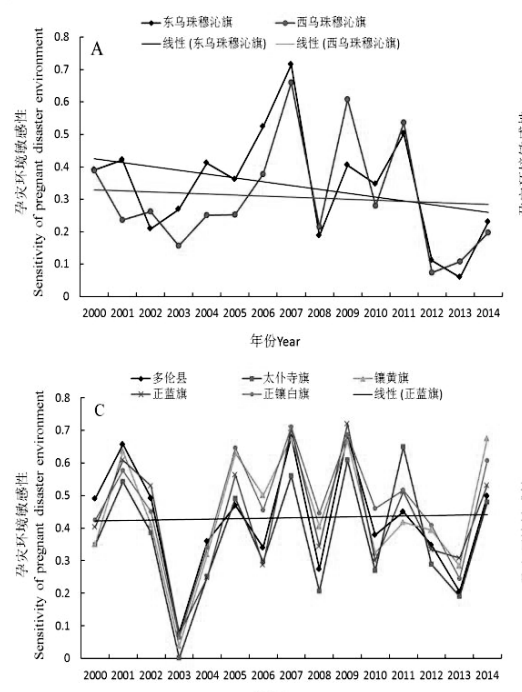

年伤Year
空间上, 干旱孕灾环境敏感性总体上表 现出由东部和南部向中西部增大的规律 (图 3 )。苏尼特右旗、二连浩特市和苏尼特左旗 干旱敏感性普遍较高, 近 15 年有 9 年 (2001 年、2002 年、2004 2006 年、2008 年、2010 年、2013 年、2014 年) 三个旗市的敏感性 均为最高等级。阿巴嘎旗、锡林浩特市和镶 黄旗干旱敏感性居中, 阿巴嘎旗和锡林浩特 市近 15 年有 7 年 (2000 年、2003 年、2005 年、2007 年、2008 2009 年、2013 年) 敏感 性居中, 镶黄旗近 15 年有 7 年（2000 年、 2002 年、 2004 年、 2008 年、2010 年、 2012 2013 年) 敏感性居中, 三个旗县市的 其它年份与其它旗县市相比均为中等敏感。 东部东西乌珠穆沁旗和南部的多伦县、太仆 寺旗、正蓝旗、正镶白旗的干旱敏感性较低, 近 15 年有 11 年 (2000 2004 年、2008 2010 年、2012 2014 年) 均为较低敏感性。由 15 年平均来看, 苏尼特右旗、二连浩特市和苏 尼特左旗干旱敏感性最高; 阿巴嘎旗、锡林 浩特市以及镶黄旗干旱敏感性居中; 而东部 的东西乌珠穆沁旗和南部的多伦县、太仆寺 旗、正蓝旗、正镶白旗的干旱敏感性较低。
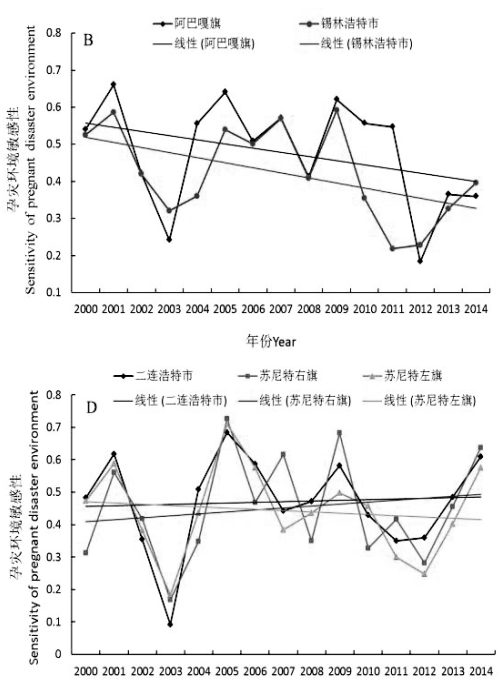

年份Year

图 2 各旗县市孕灾环境敏感性变化 


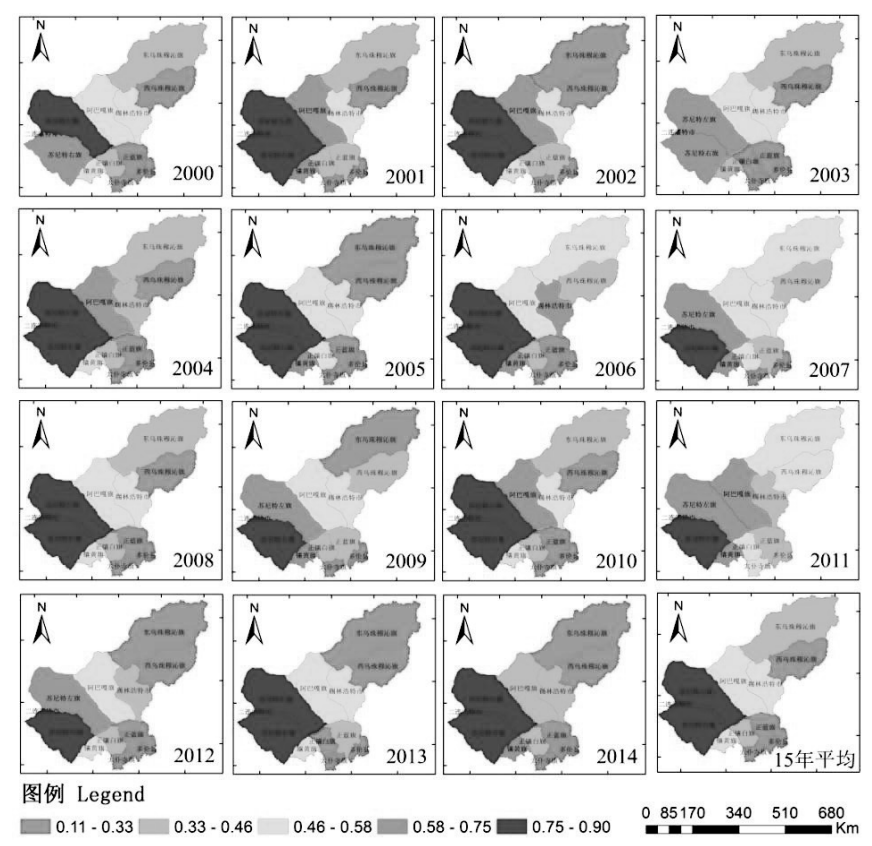

图 3 各旗县市孕灾环境敏感性空间分布

各旗县市近 15 年平均干旱孕灾环境敏 感性值在 0.21 0.85 之间变化, 由大到小排 序为: 二连浩特市 $>$ 苏尼特右旗 $>$ 苏尼特左旗 $>$ 镶黄旗 $>$ 阿巴嘎旗 $>$ 锡林浩特市 $>$ 正镶白旗 $>$ 东乌珠穆沁旗 $>$ 正蓝旗 $>$ 西乌珠穆沁旗 $>$ 多伦 县>太仆寺旗, 各旗县市之间的干旱孕灾环 境敏感性空间差异较大。

\section{3 干旱孕灾环境敏感性空间区划}

通过对各旗县市的干旱孕灾环境敏感 性分别应用最短距离法、最长距离法、中间 距离法、类平均法、重心法和离差平方和法 进行系统聚类分析, 选择出现次数最多的分 类结果形成空间区划图。当类间距离为 0.45 左右时, 锡林郭勒盟 12 个旗县市的干旱孕 灾环境敏感性聚集为以下五种类型：第一类 包括二连浩特市 (ERL)、苏尼特右旗 (SYQ) 和苏尼特左旗 (SZQ); 第二类包括锡林浩特 市 (XIL); 第三类包括阿巴嘎旗 ( $A B G$ ) 和 镶黄旗 ( $\mathrm{XHQ}$ ); 第四类包括东乌珠穆沁旗 $(D W Q) 、$ 正镶白旗 $(Z X B) 、$ 西乌珠穆沁旗 $(X W Q)$
和正蓝旗 (ZLQ); 第五类包括太仆寺旗 (TPS) 和多伦县 (DLX)。

根据聚类分析各类的平均值划分孕灾 环境敏感性的空间区划, 结果表明二连浩特 市、苏尼特右旗和苏尼特左旗是干旱敏感性 极高区域; 镶黄旗和阿巴嘎旗是干旱敏感性 较高的区域; 锡林浩特市的干旱敏感性中等; 正镶白旗、东西乌珠穆沁旗和正蓝旗干旱敏

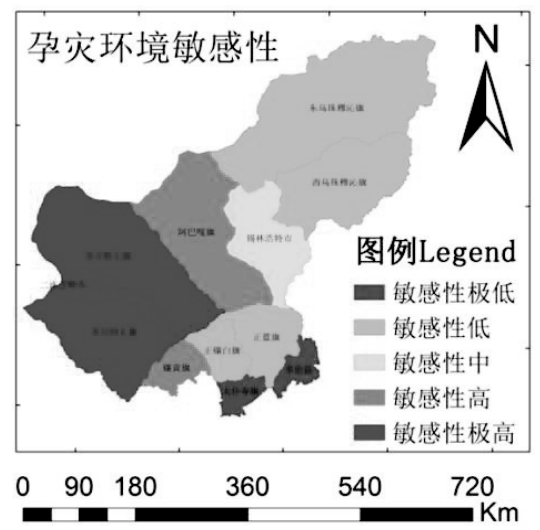

图 4 干旱孕灾环境敏感性区划 
感性较低; 多伦县和太仆寺旗是干旱敏感性 极低的区域（图 4)。

\section{4. 结论}

本文依据自然灾害风险评估理论和方 法, 从干旱孕灾环境敏感性方面选择 10 个 因子, 应用层次分析法和专家评价法相结合 确定各层指标的权重, 应用线性加权综合法 和系统聚类分析方法, 分析锡林郭勒草原干 旱孕灾环境敏感性的时空特征并进行空间 区划。

时间上, 以草甸草原为主体的东乌珠穆 沁旗和西乌珠穆沁旗的变化曲线基本一致, 以典型草原为主体的阿巴嘎旗和锡林浩特 市的变化曲线基本一致, 近 15 年以上各旗 市均呈下降趋势; 以沙地植被或农牧交错为 主体的多伦县、太仆寺旗、正蓝旗、正镶白 旗和镶黄旗变化曲线基本一致, 除多伦县呈 下降趋势外, 其余均呈上升趋势; 以荒漠草 原为主体的二连浩特市、苏尼特右旗和苏尼 特左旗的变化曲线基本一致, 苏尼特左旗呈 下降趋势, 二连浩特市和苏尼特右旗呈上升 趋势; 但各旗县市变化均不显著 $(P>0.05)$ 。

空间上, 干旱灾害敏感性表现出由东部 和南部向中西部增大的规律; 各旗县市 15 年平均孕灾环境敏感性值在 $0.21 \sim 0.85$ 之间 变化, 各旗县市之间的干旱孕灾环境敏感性 差异较大。二连浩特市、苏尼特右旗和苏尼 特左旗是干旱敏感性极高区域; 镶黄旗和阿 巴嘎旗是干旱敏感性较高的区域; 锡林浩特 市的干旱敏感性中等; 正镶白旗、东西乌珠 穆沁旗和正蓝旗干旱敏感性较低; 多伦县和 太仆寺旗是干旱敏感性极低的区域。

\section{致谢}

本研究得到中国农业科学院创新工程 “草 原非生物灾害防灾减灾团队” (CAAS-ASTIP-IGR2015-04), 内蒙古自治区 高等学校科研项目 (NJZY17047), 内蒙古自 治区自然科学基金（2017MS0408）和国家自 然科学基金（41661009）资助。

\section{参考文献:}

[1]史培军. 再论灾害研究的理论与实践. 自 然灾害学报. 1996, 11(4): 6-17.
[2]史培军. 三论灾害研究的理论与实践. 自 然灾害学报. 2002, 11(3): 1-9.

[3]史培军. 四论灾害系统研究的理论与实践. 自然灾害学报. 2005, 14(6): 1-7.

[4]黄崇福. 自然灾害风险分析的基本原理. 自然灾害学报. 1999, 8(2): 21-30.

[5]黄崇福, 刘安林, 王野. 灾害风险基本定 义的探讨.自然灾害学报. 2010, 19(6): 8-16.

[6]黄崇福. 自然灾害动态风险分析基本原理 的探讨. 灾害学. 2015, 30(2): 1-7.

[7]张继权, 冈田宪夫, 多多纳裕一. 综合自 然灾害风险管理一全面整合的模式与中 国的战略选择.自然灾害学报. 2006, 15(1): 29-37.

[8]张继权, 严登华, 王春乙, 等. 辽西北地 区农业干旱灾害风险评价与风险区划 研究. 防灾减灾工程学报. 2012, 32(3): 300-306.

[9]金菊良, 丽健强, 周玉良, 等. 旱灾风险 评估的初步理论框架. 灾害学, 2014(3): $1-10$.

[10]金菊良，宋占智，崔毅，等. 旱灾风险评 估与调控关键技术研究进展. 水利学报, 2016, 47(3):398-412.

[11]Wei Zhu,Qiuju You. High-rise building group regional fire assessment model based on AHP. Journal of Risk Analysis and Crisis Respnse.2016(6):31-37.

[12]蒙古学百科全书地理卷编辑委员会. 蒙 古学百科全书. 地理卷. 呼和浩特: 内蒙 古人民出版社,2012.

[13]锡林郭勒盟志编纂委员会.锡林郭勒盟志. 上.呼和浩特: 内蒙古人民出版社, 1996. 